\title{
Việt Nam từng bước đổi mới:
}

\section{Báo cáo của Clarivate Derwent về sự đổi mới ở Nam Á và Đông Nam Á}

\author{
Nguyễn Đức Huy
}

Nam Á và Đông Nam Á đang trên đà tăng trương kinh tế thông qua đổi mới sáng tạo. Cùng với dòng chảy của khu vục, Việt Nam cũng trải qua nhiều thăng trầm và biến động $[1,2]$. Sau khi chính sách Đổi Mới được ban hành và nhiều nỗ lục hội nhập quốc tế được xúc tiến, nước ta đã đạt được nhiều thành tưu trong khoa học, công nghệ [3,4]. Báo cáo mói của Clarivate Derwent đã nêu tên 235 tổ chức sáng tạo của khu vục, trong đó Việt Nam ghi danh với 7 tổ chưcc.

\section{Bối cảnh khu vực}

Nam Á và Đông Nam Á là một khu vực rất năng động và đa dạng. Nam Á bao gồm tám quốc gia - Afghanistan, Bangladesh, Bhutan, Ân Độ, Maldives, Nepal, Pakistan và Sri Lanka. Đông Nam Á bao gồm 11 quốc gia: Thái Lan, Campuchia, Lào, Việt Nam, Malaysia, Indonesia, Myanmar, Singapore, Philippines, Đông Timor và Brunei Darussalam. Cùng với nhau, khu vực này bao gồm 19 quốc gia gần nhau về địa lý, đa dạng về văn hóa và mỗi quốc gia đang ở các giai đoạn phát triển kinh tế khác nhau.

Nam Á và Đông Nam Á đã tận dụng nhu cầu quốc gia và nhu cầu khu vực cùng với hỗ trợ hội nhập nội khối để tham gia vào nền kinh tế toàn cầu lớn hơn, dẫn đến mở rộng thị trường, giảm chi phí thương mại và đầu tư vốn trong khu vực. Điều này đã dẫn đến tăng trưởng bao trùm hơn và đưa các nền kinh tế cận biên đến gần hơn với thị trường toàn cầu. Sự phục hồi kinh tế-xã hội kể từ những ngày xảy ra khủng hoảng tài chính châu Á là rất ấn tượng và tạo niềm tin rằng khu vực này đang đi đúng hướng. Sự công nhận đổi mới sáng tạo sẽ là động lực chính cho tăng trưởng kinh tế và cũng là thành phần quan trọng để các nước tăng trưởng bền vững trong tương lai.

\section{7 trong 235}


Theo bản bản báo cáo mới đây của Clarivate Derwent ${ }^{(1)}$, Nam và Đông Nam Á đang trên đà tăng trưởng kinh tế thông qua đổi mới sáng tạo. Nghiên cứu của Derwent đã sử dụng dữ liệu được về các bằng sáng chế từ cơ sở dữ liệu DWPI - Derwent World Patents Index ${ }^{(2)}$ (Chỉ số Sáng chế Thế giới của Derwent) và Derwent Patent Citations Index ${ }^{(3)}-\mathrm{DPCI}$ (Chỉ số Trích dẫn Bằng sáng chế Derwent) để theo dõi sự đổi mới dựa trên bốn chỉ số: số lượng, sự thành công, tính toàn cầu hóa và mức độ ảnh hưởng. Bản báo cáo là kết quả nghiên cứu đã được thực hiện trên các bằng sáng chế đăng ký lần đầu tiên trong khoảng thời gian từ năm 2014 đến năm 2018 bởi các tổ chức trên khắp khu vực Nam Á và Đông Nam Á Các tổ chức có trụ sở chính trong khu vực hoặc các tổ chức học thuật và chính phủ có nguồn gốc từ khu vực. Từ phân tích hơn 75.000 phát minh (thuộc cơ sở dữ liệu DWPI) trên toàn khu vực, 235 tổ chức đã có tên vào danh sách của những nhà đổi mới quan trọng trong khu vực với 26.339 phát minh. Các tổ chức này có trụ sở tại 9 quốc gia.

Trong đó, Việt Nam có 7 tổ chức bao gồm các viện nghiên cứu của chính phủ, cơ sở giáo dục, viện hàn lâm và các tập đoàn khác nhau. 7 tổ chức của Việt Nam bao gồm:

1. Tập đoàn FPT;

2. Công ty TNHH MTV Thoát nước và Phát triển đô thi Bà Rịa Vũng Tàu;

3. Đại học Bách Khoa Hà Nội;

4. Viện Hàn lâm Khoa học và Công nghệ Việt Nam;

5. Đại học quốc gia TP. Hồ Chí Minh;

6. Viện Nghiên Cứu Điện tử, Tin học, Tự động hoá;

7. Tập đoàn Công nghiệp - Viễn thông Quân đội (Viettel).

\section{Việt Nam và các hạng mục}

Để một tổ chức có thể ghi tên trong danh sách những nhà đổi mới, cần đáp ứng được 4 tiêu chí: số lượng sáng chế; mức độ ảnh hưởng; sự thành công và sự toàn cầu hóa. Trong đó:

- Về số lượng: Derwent xét duyệt các tổ chức có số lượng tối thiểu 20 sáng chế được nộp lần đầu tiên trong khoảng thời gian từ năm 2014 đến năm 2018. 
- Về mức độ ảnh hưởng: Derwent đã đo lường số lượng trích dẫn thông qua Derwent Patent Citations Index đối với mỗi công ty hoặc tổ chức để đánh giá mức độ ảnh hưởng của bằng sáng chế lên các đơn xin cấp bằng sáng chế sau này.

- Về sự thành công: không phải mọi đơn đăng ký sáng chế nộp cho văn phòng cấp bằng sáng chế đều được chấp thuận. Vì vậy, Derwent đã đánh giá các phát minh thuộc cơ sở dữ liệu DWPI với ít nhất một bằng sáng chế được cấp phép.

- Về tính toàn cầu hóa: Mức độ đầu tư của người nộp đơn xin cấp bằng sáng chế vào sáng chế của họ được thể hiện thông qua quá trình đầu tư để theo đuổi sự bảo hộ trên toàn cầu. Cũng vì lí do trên, Derwent đã đo lường số lượng phát minh (cơ sở dữ liệu DWPI) đã được nộp ở nhiều hơn một khu vực tài phán.

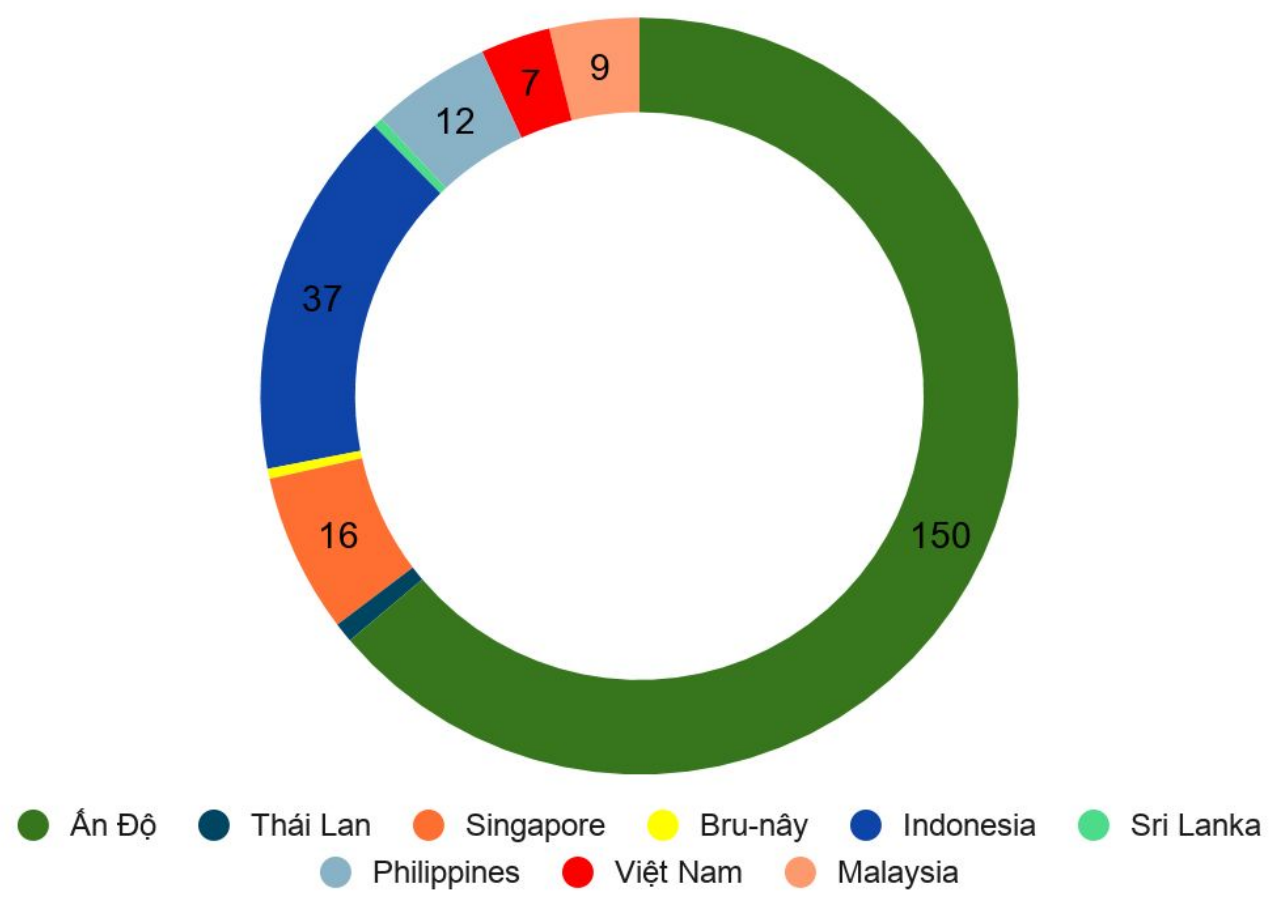

Ảnh: Việt Nam đứng thư 6 về số lượng các tổ chức đổi mới trong khu vục Nam Á và Đông Nam Á với 7 tổ chức.

Trong số 7 tổ chức của Việt Nam, có 3 tổ chức được ghi danh vào 3 hạng mục thuộc “Những nhà đổi mới dẫn đầu tại Nam Á và Đông Nam Á”, trong đó: 
- Hạng mục Tập đoàn dẫn đầu: Tập đoàn Công nghiệp - Viễn thông Quân đội (Viettel). Trong hạng mục này, các tập đoàn thuộc sở hữu của chính phủ hoặc tư nhân và có trụ sở chính trong khu vực đã được đưa vào để phân tích.

- Hạng mục Co sở giáo dục dẫn đầu: Đại học Bách Khoa Hà Nội. Để hình thành danh sách hạng mục, các cơ sở giáo dục dành riêng cho giáo dục và nghiên cứu, chẳng hạn như các trường cao đẳng, đại học và bách khoa được đưa vào để phân tích.

- Hạng mục Viện nghiên cứu chính phủ dẫn đầu: Viện Hàn lâm Khoa học và Công nghệ Việt Nam. Đây là hạng mục mà các viện hoặc cơ quan quốc gia do chính phủ thành lập để nghiên cứu, thúc đẩy và phát triển khoa học và công nghệ đã được đưa vào để phân tích.

\section{Tiến bước trên con đường đổi mới}

Việc Việt Nam ghi danh vào danh sách các nhà đổi mới ở Nam Á và Đông Nam Á với 7 tổ chức là một thành tựu lớn dành cho công cuộc phát triển giáo dục và nghiên cứu ở Việt Nam. Nhằm thúc đẩy sự đổi mới ở Việt Nam cũng như các nước Nam Á và Đông Nam Á, Clarivate Derwent đã đưa ra 5 kết luận từ bản báo cáo:

1. Các chính sách và chương trình của chính phủ sẽ đóng một vai trò quan trọng trong việc thúc đẩy văn hóa đổi mới. Đầu tư hơn nữa vào khoa học và công nghệ sẽ là công cụ quan trọng thúc đẩy nghiên cứu và đổi mới chất lượng.

2. Các mô hình kinh doanh sẽ bị phá vỡ để đáp ứng các yêu cầu của thị trường và giải quyết các thách thức của khách hàng. Từ đó tạo tiền lệ cho sự đổi mới xuất hiện từ khu vực có thể ứng dụng cho thế giới.

3. Những tiến bộ kỹ thuật số sẽ thúc đẩy sự chấp nhận của người tiêu dùng dễ dàng hơn, tạo ra quy mô để doanh nghiệp mở rộng sang các thị trường khác nhau. Điều này cũng sẽ đặt nền tảng cho sự đổi mới trong các cơ quan chính phủ và các văn phòng sở hữu trí tuệ (Intellectural Property - IP) nhằm thúc đẩy hiệu quả hoạt động. 
4. Sự đồng sáng tạo thông qua hợp tác và quan hệ đối tác sẽ đóng vai trò quan trọng trong việc tạo ra hệ sinh thái cho đổi mới.

5. Sở hữu trí tuệ sẽ là động lực cơ bản cho tăng trưởng và thịnh vượng trong khu vực.

\section{Chú thích:}

(1) Clarivate Derwent là một công ty thuộc Clarivate Analytics, hỗ trợ vòng đời đổi mới từ ý tưởng đến thương mại hóa - với dữ liệu bằng sáng chế, ứng dụng và dịch vụ đáng tin cậy bao gồm Derwent Innovation, Derwent World Patents Index, Derwent Patents Citation Index và Derwent Data Analyzer. Clarivate Derwent xây dựng các giải pháp cho các nhà phát minh, luật sư bằng sáng chế và chuyên gia cấp phép tại các công ty khởi nghiệp và các nhà đổi mới lớn nhất toàn cầu, các chuyên gia pháp lý tại các cơ sở thực hành sở hữu trí tuệ hàng đầu và những người giám định bằng sáng chế tại hơn 40 văn phòng cấp bằng sáng chế.

(2) Derwent World Patents Index là cơ sở dữ liệu về các bằng sáng chế và đơn đăng ký sáng chế từ 60 quốc gia và cơ quan có thẩm quyền cấp bằng sáng chế.

(3) Derwent Patents Citation Index là một cơ sở dữ liệu có liên quan với DWPI, Chỉ số trích dẫn bằng sáng chế của Derwent tập trung vào các phát minh đã được người nộp đơn và người thẩm định bằng sáng chế tham khảo trong các đơn xin cấp bằng sáng chế.

\section{Tài liệu tham khảo:}

[1] Phạm Minh Chính \& Vương Quân Hoàng. (2009). Kinh tế Việt Nam: Thăng trầm và đột phá. Nxb Chính trị Quốc gia, Hà Nội.

[2] Phạm Minh Chính \& Vương Quân Hoàng. (2008). Bối cảnh tài chính Việt Nam 1997-1998 và 2007-2008: Khoảng cách và biến đối. Nghiên cứu Kinh tế, 48(7), 3-24. 
[3] Vuong, Q. H. (2018). The (ir) rational consideration of the cost of science in transition economies. Nature Human Behaviour 2 (1), 5, doi: 10.1038/s41562-017-0281-4.

[4] Vuong, Q. H., Bui, A. T., La, V. P., Nguyen, M. H., Pham, H. H., Pham, T. H., ... $\&$ Ho, M. T. (2021). Mirror, mirror on the wall: Is economics the fairest of them all? An investigation into the social sciences and humanities in Vietnam. Research Evaluation.

[5] Clarivate Derwent. (2020). Innovation in South and South East Asia. Clarivate. 